\section{EASD}

Procedia
EURODYN 2020

XI International Conference on Structural Dynamics M. Papadrakakis, M. Fragiadakis, C. Papadimitriou (eds.)

\title{
MEASUREMENTS OF THE COLOSSEUM RESPONSE TO ENVIRONMENTAL ACTIONS
}

\author{
Fabrizio Vestroni ${ }^{1}$, Adriano De Sortis ${ }^{2}$ and Annamaria Pau ${ }^{1}$ \\ ${ }^{1}$ Sapienza University of Rome \\ Via Eudossiana, Roma \\ e-mail: vestroni@uniroma1.it, annamaria.pau@uniroma1.it \\ ${ }^{2}$ Department of Civil Protection \\ Via Vitorchiano 2, Roma \\ e-mail: adriano.desortis@protezionecivile.it
}

Keywords: Cultural heritage structures, Monitoring, Modal analysis, Seismic behaviour.

\begin{abstract}
The Colosseum is the most famous monument of ancient Rome. Differential settlements of its foundations, standing partly on alluvial deposits and partly on stiff soil, and various earthquakes are the main causes of collapses that give the Colosseum its present shape. In order to preserve the monument, a number of structural interventions were made during the 19th century. At present, the health status of the monument requires to be monitored against possible degradation phenomena. During the preliminary design stage of a new underground line crossing the center of Rome, at present under construction, further investigations on materials properties and dynamic features have been performed. In particular, twelve accelerometers on two vertical lines in the highest portion of the monument have been installed. In the present paper data gathered with this monitoring system for a long period of time gives the opportunity of a further insight into the health conditions of the structure. The vibration levels induced by road traffic during a long interval of time and frequencies and mode shapes of low modes are identified using ambient vibration. Both these results are compared with the outcomes of an experimental campaign of a few years ago. Finally, the dynamic behaviour recorded during the 2016-2017 Central Italy seismic sequence is analysed and discussed.
\end{abstract}

ISSN:2311-9020 (C) 2020 The Authors. Published by EASD Procedia.

Peer-review under responsibility of the Organizing Committee of EURODYN 2020. doi: $10.47964 / 1120.9191 .20096$ 


\section{INTRODUCTION}

Structural Health Monitoring (SHM) has notably increased its importance in the last decades $[1,2,3]$. The spreading of this kind of activity is also due to the updating of instruments and the reduction of their cost; at the same time, theory and techniques of data processing have become more effective $[4,5,6,7,8,9]$. In this field methods based on structural vibration and their evolution are well established, also because information easily obtained using environmental excitations happens to be effective in detecting structural deterioration. In the case of large structures and cultural heritage buildings, SHM should be a must. So, it is natural that the Colosseum, the most famous monument of ancient Rome, is the object of special attention by the Superintendent of Cultural Heritage with a series of activities.

A new underground line crossing the center of Rome, at present under construction [10], run tangentially to the Colosseum; during the design stage a wide campaign of experimental investigations on materials properties and dynamic features have been performed. Moreover, the monument has been instrumented in order to develop both static and dynamic monitoring. In particular, inclinometers and estensometers to measure displacements due to temperature changes and twelve accelerometers on two vertical lines in the zone with greatest height have been installed.

The slow movements produced by temperature induce deformations and stresses, with cycles which are repeated every year. The accelerometric registrations of the ambient vibrations permit to obtain the intrinsic dynamic properties of the structure with a twofold aim. First, the comparison and correlation between experimental modal parameters and those predicted by a finite element model enable us to identify or update an accurate model of the monument; this is an important item especially where buildings of historical interest are involved, since they are often characterized by complex geometry and heterogeneity of materials. Second, the evolution in time of the modal properties gives information on possible degradation phenomena.

In this paper the main attention is devoted to the dynamic response; in particular, the vibration levels induced by road traffic for a long time interval is examined, then ambient vibrations are used to identify frequencies and shapes of low modes by these incomplete data. These results are both compared to available data obtained by the authors during an experimental campaign of a few years ago. Finally, the dynamic response to the 2016-2017 Central Italy seismic sequence is analysed and discussed.

\section{THE NEW UNDERGROUND LINE OF ROME}

The severe conditions of the surface traffic in Rome highlighted the need to improve the public transportation network. The two existing underground Lines A and B did not reach all the sectors of the city and suburbs. The authority managing the underground lines decided, in such a context, to construct the new Line $\mathrm{C}$ crossing the Rome territory along the alignment NW-SE. Figure 1, just for the intermediate part of the line, denoted as Section T3, shows the interference of the new line with some of the most famous monuments in the world. Among the others, the underground line runs near the Colosseum. Further details can be found at [10].

During the design stage, several forecasting activities have been performed, in order to simulate the effects of the underground works and to estimate the possible impacts on the monuments. For the Colosseum, the effects were estimated as negligible and no special provisional measures were provided. Nevertheless, a comprehensive monitoring system has been deployed, in order to study the response of the structure before and during the underground construction. 


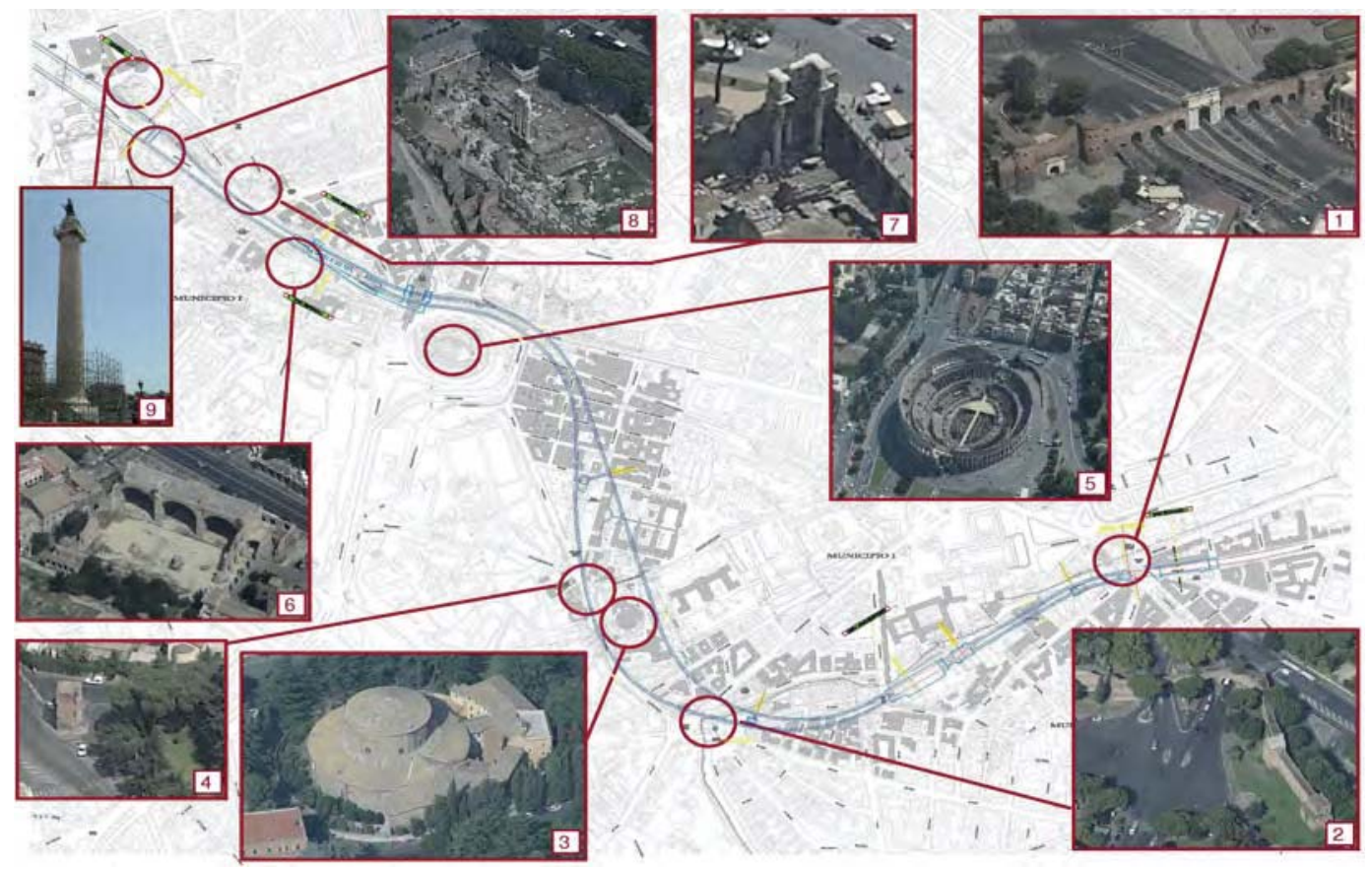

Figure 1: The Section T3 of the new Line C of Rome underground and the interference with monuments: 1) Porta Metronia, 2) Acquedotto Celimontano, 3) Basilica di S. Stefano Rotondo, 4) Porta Asinaria, 5) Colosseum, 6) Basilica di Massenzio, 7) Colonnacce, 8) Foro di Cesare, 9) Colonna Traiana.

\section{DESCRIPTION OF THE MONITORING SYSTEM}

A general description of the monitoring framework is reported in [11]. For the Colosseum, the monitoring system can be divided into 4 sections:

- topographic monitoring, aimed at gathering absolute displacements and rotations;

- geotechnical monitoring, aimed at gathering soil pore pressure and vertical and horizontal ground displacements;

- structural monitoring, divided into two subsections:

- static monitoring, aimed at gathering structure and air temperatures, existing cracks openings, relative displacements, rotations;

- dynamic monitoring, aimed at gathering structural accelerations and velocities.

The static monitoring is composed by 4 thermometers, 7 tiltmeters, 22 crackmeters and 12 wire-crackmeters. The dynamic monitoring is composed by 12 triaxial force-balance accelerometers, located along two vertical alignments, as reported in Fig. 2. The present paper is devoted to the analysis of dynamic measured quantities.

\section{ANALYSIS OF DYNAMIC MEASUREMENTS}

\subsection{Road traffic}

The main goal of the accelerometric monitoring system previously described is the survey of the vibration level during the construction of the underground line. Due to the presence of the monitoring system since the end of of 2014 and still functioning, both current vibration level 


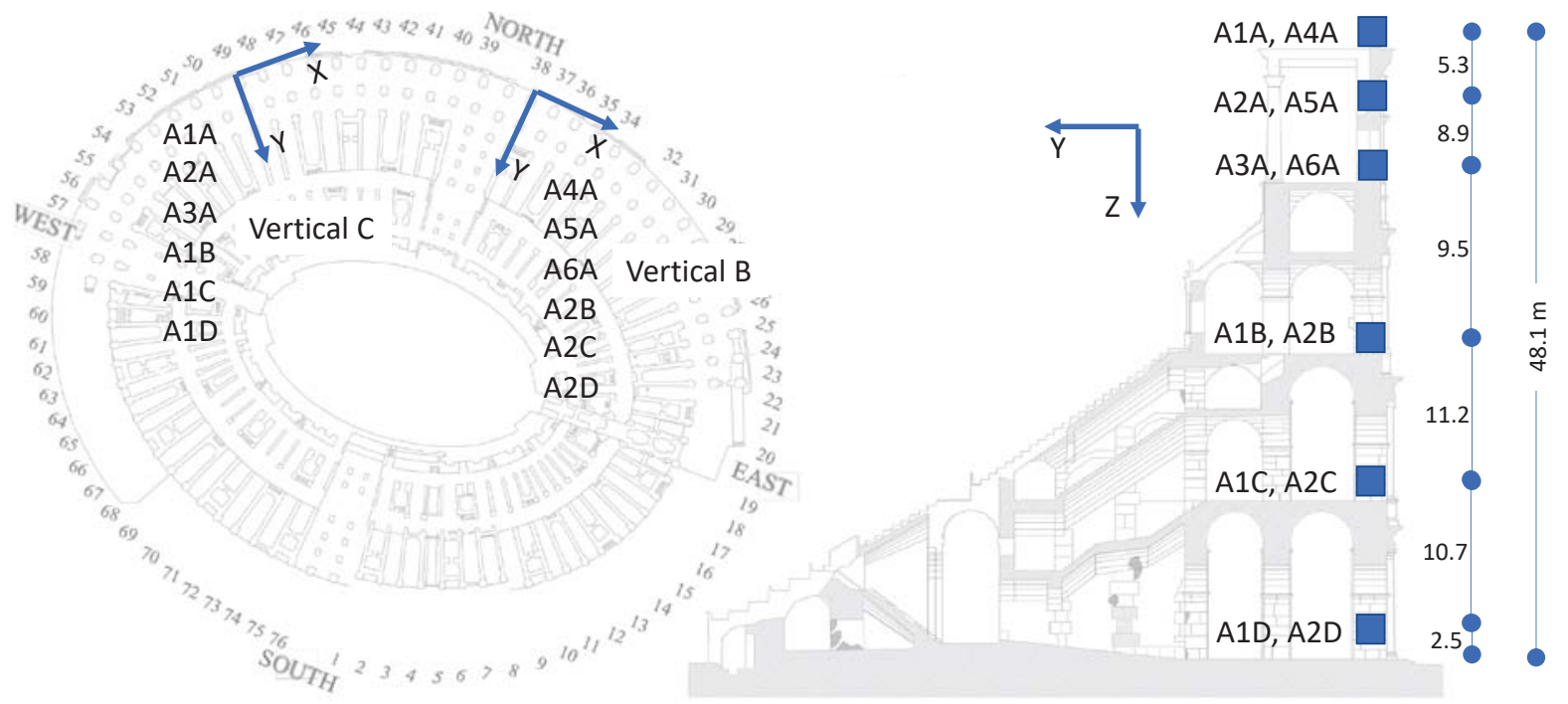

Figure 2: Locations of the accelerometric sensors and channels positive directions.

and peak values can be evaluated. A comprehensive analysis of data is outside the scope of the present paper, nevertheless a short discussion on the vibration level measured during one month (January 2020) is reported here; during this period the construction was inactive. Figure 3 shows the envelopes of the velocity recorded at the base and on the top in each direction. In vertical and circumferential directions at the base the maximum value of the velocity is about $0.15 \mathrm{~mm} / \mathrm{s}$, on top is about $0.5 \mathrm{~mm} / \mathrm{s}$, with smaller effective values respectively of about 0.02 $\mathrm{mm} / \mathrm{s}$ at the base and $0.05-0.1 \mathrm{~mm} / \mathrm{s}$ on top. In radial direction the maximum values of the velocity are similar, while the effective values are respectively of about $0.04 \mathrm{~mm} / \mathrm{s}$ at the base and $0.15 \mathrm{~mm} / \mathrm{s}$ on top. With reference to the time interval considered, the vibration level is very similar to that reported in [6] and it does not exceed the limit values reported in [12].

\subsection{Modal analysis using ambient vibration}

The experimental modal parameters have been evaluated in [6] using a large number of measurement points, under ambient vibration excitation. It was verified that the input at the base of the monument, in the frequency band 1-6 Hz, approximates a white noise. The experimental modal parameters were therefore derived from the response only, under the hypothesis of white noise excitation. In this condition, the output spectrum reaches a maximum at the natural frequencies, where the response of the structure peaks. The vibration frequencies of the first six modes, obtained in [6] by a singular value decomposition of the power spectral density matrix of the responses, are listed in Tab. 1.

\begin{tabular}{lcccccc}
\hline Mode & 1 & 2 & 3 & 4 & 5 & 6 \\
\hline Frequency [6] & 1.03 & 1.30 & 1.49 & 1.60 & 1.66 & 1.75 \\
Frequency (this study) & 1.04 & 1.28 & 1.47 & 1.62 & 1.71 & - \\
\hline
\end{tabular}

Table 1: Frequencies $(\mathrm{Hz})$ of the first modes evaluated in [6] and in the present study.

Data recorded with the new monitoring system has been used to repeat the experimental modal analysis. In the present setup, few measurements are available, especially on the top 


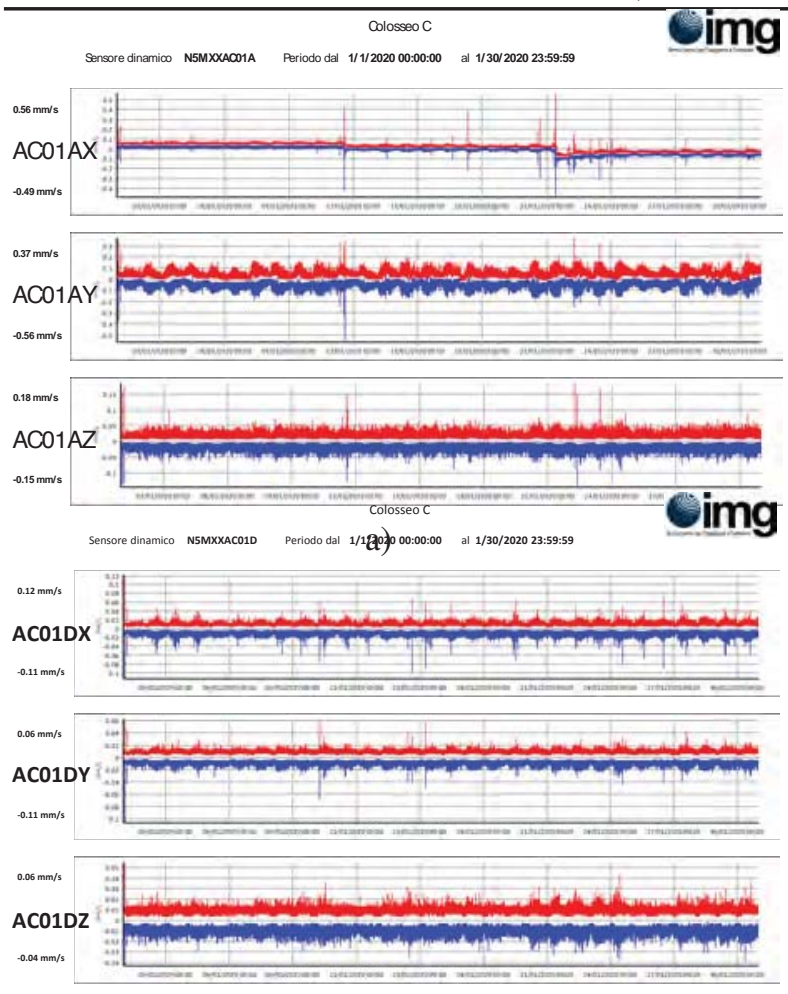

c)

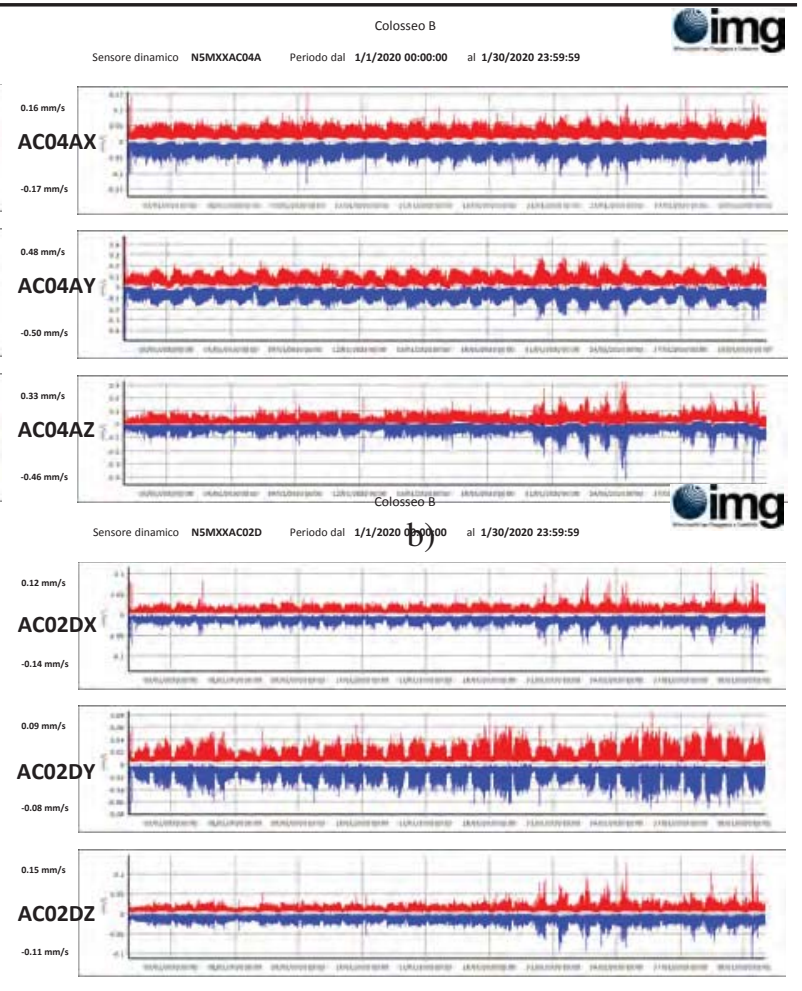

d)

Figure 3: Velocity vibration levels (mm/s) measured during January 2020; a) sensor A1A (top level); b) sensor A4A (top level); c) sensor A1D (base level); d) sensor A2D (base level); for each sensor from top to bottom X (circumferential), Y (radial) and Z (vertical).

of the structure, thus it resulted rather difficult to detect the first two modes, which mainly involve points very far from the sensors. The same techniques applied in [6] have been used. Figure 4 shows the first two singular values of the power spectral density matrix of the response, where the modes identified are indicated with black circles. A comparison between the natural frequencies is reported in Tab. 1, showing a very good agreement. Also the components of the eigenvectors common to both [6] and present test setup have been compared, obtaining an acceptable agreement. Thus, with reference to this limited comparison, it can be argued that the dynamic characteristics of the structure appear stable.

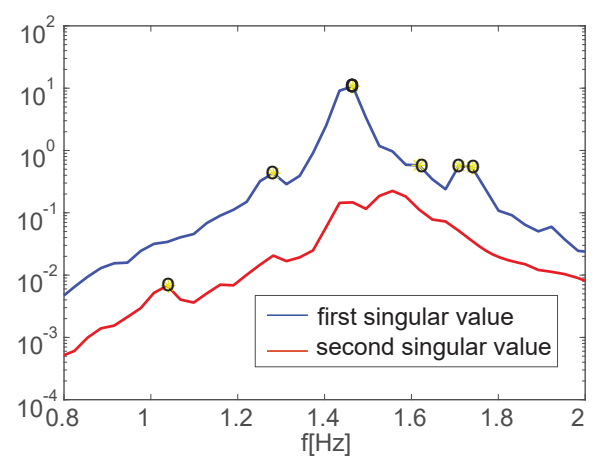

Figure 4: Singular value decomposition of the power spectral density matrix using data from ambient vibration. 
Fabrizio Vestroni, Adriano De Sortis and Annamaria Pau

\begin{tabular}{ccccccccccccccc}
\hline n. & year & month & day & hh & mm & ss & $M_{w}$ & lat & long & $\begin{array}{c}\text { depth } \\
(\mathrm{km})\end{array}$ & $\begin{array}{c}\text { dist. } \\
(\mathrm{km})\end{array}$ & $\begin{array}{c}a_{b, t} \\
(\mathrm{~g} \%)\end{array}$ & $\begin{array}{c}a_{b, r} \\
(\mathrm{~g} \%)\end{array}$ & $\begin{array}{c}a_{b, v} \\
(\mathrm{~g} \%)\end{array}$ \\
\hline 1 & 2016 & 8 & 24 & 1 & 36 & 32 & 6 & 42.7 & 13.2 & 8 & 109 & 0.32 & 0.35 & 0.23 \\
2 & 2016 & 8 & 24 & 2 & 33 & 28 & 5.3 & 42.7 & 13.2 & 8 & 105 & 0.24 & 0.19 & 0.12 \\
3 & 2016 & 10 & 26 & 17 & 10 & 36 & 5.4 & 42.9 & 13.1 & 8 & 122 & 0.31 & 0.47 & 0.17 \\
4 & 2016 & 10 & 26 & 19 & 18 & 7 & 5.9 & 42.9 & 13.1 & 10 & 120 & 0.29 & 0.39 & 0.14 \\
5 & 2016 & 10 & 30 & 6 & 40 & 17 & 6.5 & 42.8 & 13.1 & 10 & 116 & 0.95 & 0.94 & 0.41 \\
6 & 2017 & 1 & 18 & 9 & 25 & 40 & 5.1 & 42.5 & 13.3 & 10 & 97 & 0.09 & 0.14 & 0.08 \\
7 & 2017 & 1 & 18 & 10 & 14 & 9 & 5.5 & 42.5 & 13.3 & 10 & 96 & 0.19 & 0.36 & 0.13 \\
8 & 2017 & 1 & 18 & 10 & 25 & 23 & 5.4 & 42.5 & 13.3 & 9 & 94 & 0.24 & 0.33 & 0.13 \\
9 & 2017 & 1 & 18 & 13 & 33 & 36 & 5 & 42.5 & 13.3 & 10 & 92 & 0.1 & 0.2 & 0.08 \\
\hline
\end{tabular}

Table 2: Events with magnitude $M_{w}>5$ during the 2016-2017 Central Italy seismic sequence; the distances are computed between the epicenters and the Colosseum; $a_{b, t}, a_{b, r}$ and $a_{b, v}$ (measured in $\mathrm{g} * 100$ ) are the peak base accelerations recorded by the monitoring system respectively along the tangential, radial and vertical directions.

\subsection{Response to 2016-2017 Central Italy seismic sequence}

The measured response of a structure when it is impacted by a significant earthquake often furnishes significant information about its characteristics and health conditions [13,14]. During 2016 and 2017, Central Italy has been interested by a significant seismic sequence. The accelerometric monitoring network was already deployed on the monument, thus several records of the structural response are available. Here, only events with magnitude greater than 5 have been considered. The main characteristics of these events are listed in Tab. 2. The epicenters are rather far from the Colosseum, with distances ranging from 92 to $122 \mathrm{~km}$. The maximum value of the acceleration recorded at the base is about $0.01 \mathrm{~g}$ in the horizontal direction and $0.004 \mathrm{~g}$ in the vertical direction. The event that produced maximum accelerations at the base occurred on 2016, October 30, with a magnitude of 6.5 (event no. 5 in Tab. 2).

Figure 5 shows the 5\% damping acceleration response spectra of event no. 5, as recorded at the monument base at two points in two directions. Modes 3 to 6 are located in the maximum amplification range of the spectra. In order to have a rough evaluation of the level of shaking, one could consider that, according to current seismic regulations, the 475-year return period site response spectrum on stiff soil has spectral ordinates respectively of $0.15,0.23$ and $0.1 \mathrm{~g}$ at 0 , 0.5 and $1 \mathrm{~s}$. Thus, in terms of elastic response spectrum, event no. 5 produced about $1 / 10$ of the spectral accelerations expected for the design earthquake.

Table 3 lists maximum accelerations recorded in radial directions. As expected, the peak values have been attained at the top level (about $0.09 \mathrm{~g}$ ). It is interesting also to note that the dynamic amplification, i.e. the ratio between top and base peak accelerations, decreases when base peak acceleration increases. At any rate, the minimum dynamic amplification in radial direction is about 8.5 . Thus, in the hypothesis of linear behaviour, a 475 -year earthquake could lead to top accelerations up to about $1.3 \mathrm{~g}$. This highlights the seismic vulnerability of the monument in its actual configuration, which probably requires a study for a mitigation intervention. In circumferential direction (Tab. 3) maximum accelerations of about 0.02-0.03 $\mathrm{g}$ have been recorded. Also in this direction the minimum amplification factor is about 3.6, a value rather common for masonry structures. Maximum recorded accelerations in vertical direction, not reported here, exhibits a minimum amplification factor of 2.4.

The configuration of the accelerometric monitoring system allows us to estimate a drift parameter that can be related to the strain level of the structure, i.e. the relative displacement between two sensors on the same vertical divided by their distance. Table 4 lists this quantity 


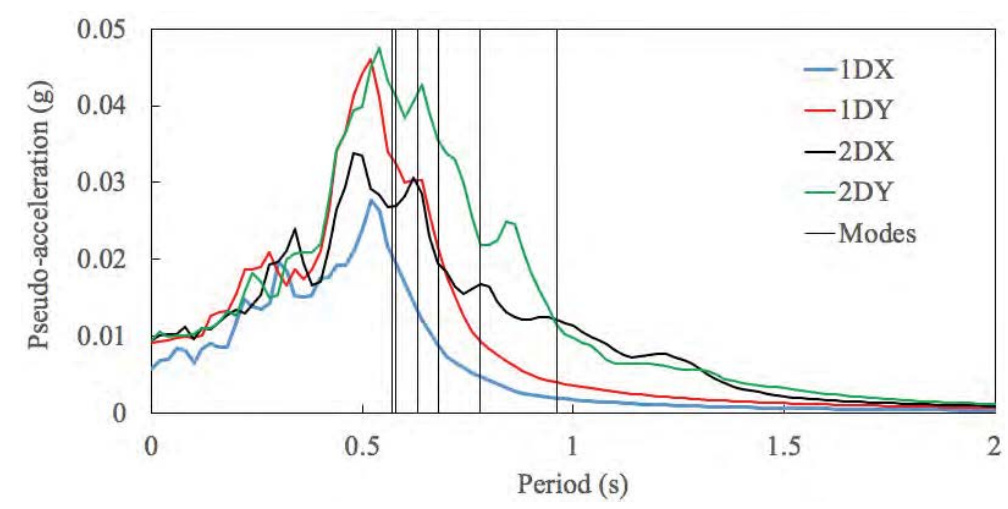

Figure 5: Response spectra at 5\% damping of the accelerations recorded at the base during the event n. 5 of Tab. 2; the first letter A of the sensor labels is omitted; the directions $X$ and $Y$ are reported in Fig. 2; the vertical lines correspond to the first 6 modes of the structure.

for both horizontal directions. The graphical representation of Fig. 6 highlights that, in the plane of the facade, a strain concentration occurs on the third order of openings. In the out-of-plane direction, the upper part of the facade exhibits almost constant values. This behaviour is common to all 9 seismic events studied here. With reference to the strongest event no. 5 of Tab. 2 , it was verified that the drift parameters of the upper sections are in phase and the maximum values are simultaneously attained, thus the behaviour is that of an almost rigid rotation. The rotation center is located at the base of the third order openings, which can be considered the most stressed part of the structure, both in plane and out of plane, during an earthquake.

\section{CONCLUSIONS}

The new Line $\mathrm{C}$ of Rome underground passes near the Colosseum. Owing to the historical renown of this ancient monument, the General Contractor, on behalf of Superintendent of Cultural Heritage, decided to perform a series of experimental activities to investigate its health conditions; in particular, static and dynamic instruments were used to monitor the structure before, during and after the underground construction.

In this study the focus was on five-year recordings of the dynamic quantities, accelerations and velocities, available to date, considering three different groups of results: the traffic induced vibration, the ambient vibration and the response to a recent seismic sequence in Central Italy.

As far as the velocities caused by the traffic, the levels of the results processed are very similar to those measured in a previous experimental campaign conducted by two of the authors in 2005, and, mainly, the maximum amplitude is below the levels known to cause damage, according to international guidelines.

As far as the ambient vibration, the procedures of the experimental modal analysis are used to identify frequencies and modes components at measurement points. Also in this case the dynamic properties obtained are in good agreement with those determined in 2005, leading to the preliminary conclusion that no overall deterioration phenomena recently occurred.

The registrations of accelerations produced by the seismic sequence of 2016-2017 in Central Italy are of some interest because they are the only available recordings of the earthquake effects on the monument. Notwithstanding the epicenter is far from the Colosseum, around $100 \mathrm{~km}$, the measurements are sufficiently clear, with non-negligible response peaks. For the recorded earthquakes the maximum amplification of the spectrum is observed in a frequency band which 


\begin{tabular}{ccccccccccccc}
\hline n. & $1 \mathrm{AY}$ & $2 \mathrm{AY}$ & $3 \mathrm{AY}$ & $4 \mathrm{AY}$ & $5 \mathrm{AY}$ & $6 \mathrm{AY}$ & $1 \mathrm{BY}$ & $2 \mathrm{BY}$ & $1 \mathrm{CY}$ & $2 \mathrm{CY}$ & $1 \mathrm{DY}$ & $2 \mathrm{DY}$ \\
\hline 1 & 3.48 & 2.28 & 1.24 & 5.8 & 3.09 & 1.29 & 0.63 & 0.8 & 0.47 & 0.41 & 0.35 & 0.27 \\
2 & 2.53 & 1.68 & 0.81 & 2.59 & 1.46 & 0.87 & 0.40 & 0.53 & 0.25 & 0.30 & 0.20 & 0.19 \\
3 & 4.04 & 2.66 & 1.19 & 4.88 & 2.68 & 1.25 & 0.81 & 0.77 & 0.62 & 0.51 & 0.47 & 0.41 \\
4 & 3.23 & 1.96 & 0.7 & 5.56 & 3.13 & 1.67 & 0.66 & 0.88 & 0.45 & 0.5 & 0.34 & 0.39 \\
5 & 9.27 & 3.85 & 1.71 & 9.41 & 6.06 & 2.52 & 1.82 & 1.96 & 1.25 & 1.36 & 0.91 & 0.94 \\
6 & 1.42 & 1.05 & 0.69 & 1.24 & 0.63 & 0.55 & 0.28 & 0.29 & 0.19 & 0.16 & 0.14 & 0.1 \\
7 & 2.99 & 2.01 & 0.97 & 2.8 & 1.34 & 0.62 & 0.74 & 0.59 & 0.5 & 0.41 & 0.36 & 0.28 \\
8 & 3.43 & 2.41 & 1.52 & 3.95 & 1.75 & 1.1 & 0.67 & 0.66 & 0.47 & 0.38 & 0.33 & 0.24 \\
9 & 1.05 & 0.62 & 0.31 & 1.7 & 1.26 & 0.63 & 0.35 & 0.34 & 0.22 & 0.24 & 0.13 & 0.2 \\
\hline & & & & & & & & & & & & \\
\hline n. & $1 \mathrm{AX}$ & $2 \mathrm{AX}$ & $3 \mathrm{AX}$ & $4 \mathrm{AX}$ & $5 \mathrm{AX}$ & $6 \mathrm{AX}$ & $1 \mathrm{BX}$ & $2 \mathrm{BX}$ & $1 \mathrm{CX}$ & $2 \mathrm{CX}$ & $1 \mathrm{DX}$ & $2 \mathrm{DX}$ \\
\hline 1 & 0.95 & 0.87 & 0.84 & 1.42 & 1.25 & 1.29 & 0.92 & 1.35 & 0.51 & 0.74 & 0.27 & 0.32 \\
2 & 0.52 & 0.55 & 0.55 & 0.91 & 0.87 & 0.81 & 0.53 & 0.64 & 0.31 & 0.43 & 0.17 & 0.24 \\
3 & 0.89 & 0.97 & 0.99 & 1.1 & 1.11 & 1.05 & 0.73 & 0.9 & 0.48 & 0.57 & 0.31 & 0.31 \\
4 & 0.81 & 0.81 & 0.79 & 1.76 & 1.45 & 1.37 & 0.5 & 1 & 0.36 & 0.64 & 0.23 & 0.29 \\
5 & 2.13 & 2.16 & 2.1 & 3.4 & 2.99 & 2.88 & 1.34 & 2.56 & 1.15 & 1.85 & 0.57 & 0.95 \\
6 & 0.38 & 0.36 & 0.33 & 0.46 & 0.42 & 0.42 & 0.38 & 0.4 & 0.19 & 0.22 & 0.09 & 0.08 \\
7 & 0.96 & 0.96 & 0.93 & 1 & 0.85 & 0.86 & 0.56 & 0.76 & 0.28 & 0.51 & 0.17 & 0.19 \\
8 & 0.87 & 0.85 & 0.79 & 1.22 & 1.04 & 1.02 & 0.91 & 0.98 & 0.43 & 0.52 & 0.24 & 0.17 \\
9 & 0.45 & 0.45 & 0.44 & 0.52 & 0.44 & 0.45 & 0.22 & 0.44 & 0.12 & 0.18 & 0.07 & 0.1 \\
\hline
\end{tabular}

Table 3: Maximum accelerations in ( $\mathrm{g} * 100)$ recorded by the monitoring system in radial (Y) and circumferential (X) directions during the events described in Tab. 2; the first letter A of the sensor labels is omitted.

\begin{tabular}{ccccccccccc}
\hline $\mathrm{n}$. & $1 \mathrm{AY}$ & $2 \mathrm{AY}$ & $3 \mathrm{AY}$ & $4 \mathrm{AY}$ & $5 \mathrm{AY}$ & $6 \mathrm{AY}$ & $1 \mathrm{BY}$ & $2 \mathrm{BY}$ & $1 \mathrm{CY}$ & $2 \mathrm{CY}$ \\
\hline 1 & 0.145 & 0.113 & 0.181 & 0.227 & 0.176 & 0.196 & 0.009 & 0.018 & 0.008 & 0.008 \\
2 & 0.103 & 0.079 & 0.111 & 0.113 & 0.099 & 0.103 & 0.007 & 0.015 & 0.004 & 0.006 \\
3 & 0.14 & 0.106 & 0.166 & 0.175 & 0.134 & 0.186 & 0.01 & 0.021 & 0.01 & 0.01 \\
4 & 0.11 & 0.077 & 0.063 & 0.208 & 0.164 & 0.164 & 0.009 & 0.026 & 0.007 & 0.011 \\
5 & 0.329 & 0.19 & 0.158 & 0.472 & 0.413 & 0.344 & 0.026 & 0.048 & 0.021 & 0.028 \\
6 & 0.046 & 0.039 & 0.068 & 0.044 & 0.038 & 0.034 & 0.005 & 0.005 & 0.003 & 0.003 \\
7 & 0.094 & 0.072 & 0.089 & 0.099 & 0.069 & 0.061 & 0.011 & 0.013 & 0.009 & 0.007 \\
8 & 0.117 & 0.094 & 0.162 & 0.143 & 0.107 & 0.078 & 0.014 & 0.016 & 0.007 & 0.009 \\
9 & 0.03 & 0.023 & 0.028 & 0.067 & 0.066 & 0.079 & 0.005 & 0.007 & 0.004 & 0.004 \\
\hline & & & & & & & & & & \\
\hline $\mathrm{n}$. & $1 \mathrm{AX}$ & $2 \mathrm{AX}$ & $3 \mathrm{AX}$ & $4 \mathrm{AX}$ & $5 \mathrm{AX}$ & $6 \mathrm{AX}$ & $1 \mathrm{BX}$ & $2 \mathrm{BX}$ & $1 \mathrm{CX}$ & $2 \mathrm{CX}$ \\
\hline 1 & 0.012 & 0.007 & 0.096 & 0.073 & 0.011 & 0.106 & 0.047 & 0.045 & 0.02 & 0.027 \\
2 & 0.008 & 0.005 & 0.078 & 0.038 & 0.006 & 0.075 & 0.029 & 0.024 & 0.014 & 0.012 \\
3 & 0.011 & 0.005 & 0.082 & 0.057 & 0.009 & 0.108 & 0.037 & 0.035 & 0.016 & 0.02 \\
4 & 0.007 & 0.004 & 0.046 & 0.067 & 0.009 & 0.105 & 0.019 & 0.033 & 0.009 & 0.022 \\
5 & 0.022 & 0.009 & 0.128 & 0.158 & 0.018 & 0.309 & 0.038 & 0.066 & 0.025 & 0.062 \\
6 & 0.004 & 0.004 & 0.039 & 0.013 & 0.002 & 0.025 & 0.02 & 0.009 & 0.009 & 0.006 \\
7 & 0.007 & 0.005 & 0.061 & 0.024 & 0.003 & 0.064 & 0.027 & 0.013 & 0.011 & 0.013 \\
8 & 0.01 & 0.009 & 0.128 & 0.034 & 0.003 & 0.073 & 0.048 & 0.02 & 0.024 & 0.014 \\
9 & 0.002 & 0.001 & 0.023 & 0.03 & 0.005 & 0.04 & 0.008 & 0.014 & 0.004 & 0.006 \\
\hline
\end{tabular}

Table 4: Maximum relative displacements divided by the distance between two sensors $(\mathrm{mm} / \mathrm{m})$ recorded by the monitoring system in radial (Y) and circumferential (X) directions during the events described in Tab. 2; the labels of the columns correspond to the upper sensor; the first letter A of the sensor labels is omitted. 


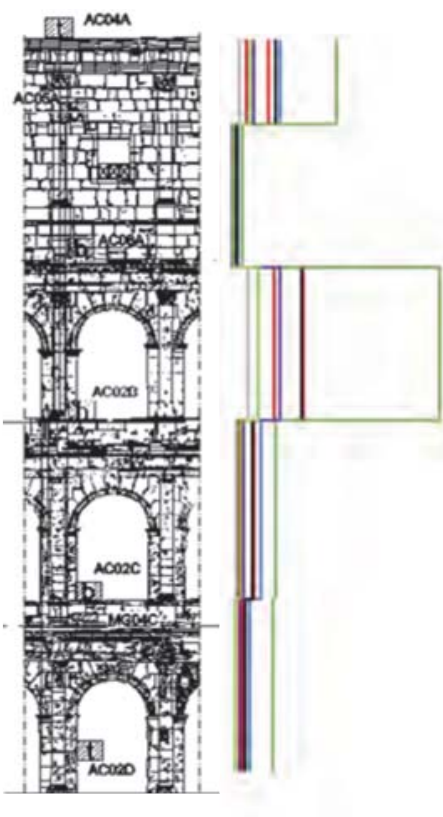

a)

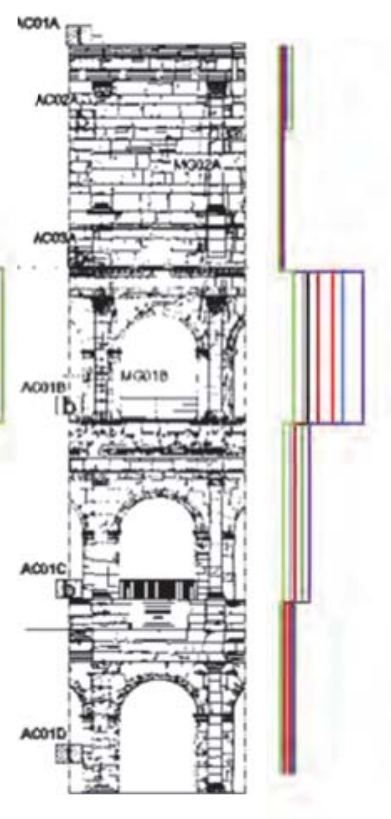

b)

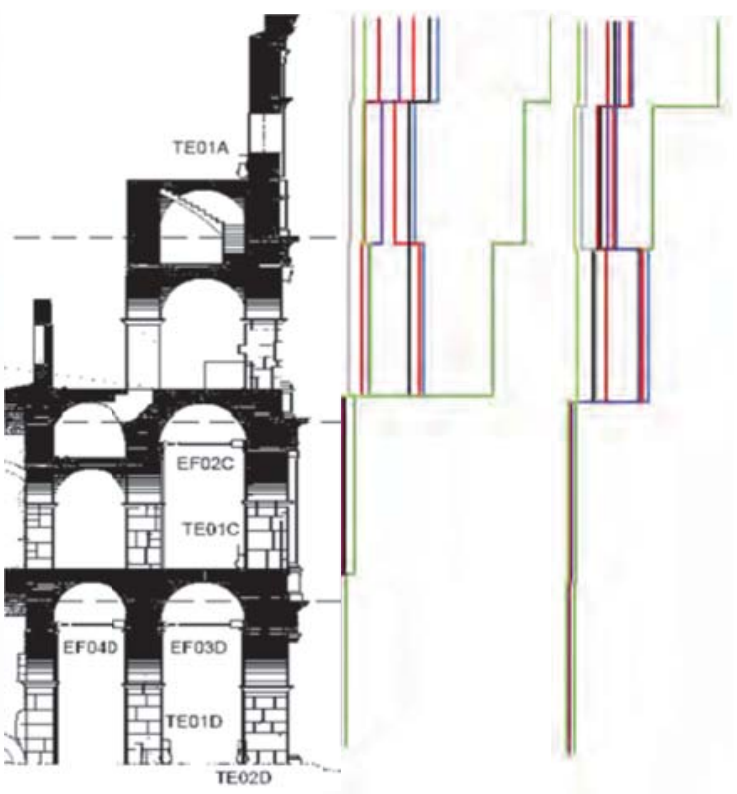

c)

d)

Figure 6: Relative displacements divided by the distance between two sensors recorded by the monitoring system during the events of Tab. 2; a) Vertical B of Fig.2, radial direction ; b) Vertical C, radial direction; c) Vertical B, circumferential direction; d) Vertical C, circumferential direction.

does not involve the first two modes of the monument, localized mainly at Valadier's and Stern's buttresses, which are the most dangerous. These results are important because they make it possible to use an updated finite element model to interpret these data and to predict the response to the expected earthquakes in Rome, evaluating the actual risk of the monument.

\section{ACKNOWLEDGEMENTS}

The experimental data have been made available by Metro C S.C.p.A., General Contractor of the Line $\mathrm{C}$ of the Rome Underground. The cooperation of Design Manager Eliano Romani and Dr. Ivan Mammone are gratefully acknowledged. Moreover, the valuable contribution of Eng. Matteo Ruggeri of IMG S.r.l. that manages the monitoring system is acknowledged.

This work has been partially supported by the MIUR (Ministry of Education, University and Research) under the Project PRIN 2015-2018, P.I. Fabrizio Vestroni, "Identification and Monitoring of Complex Structural Systems".

\section{DISCLAIMER}

The views and conclusions contained here are those of the authors, and should not be interpreted as necessarily representing official policies, either expressed or implied, of the Italian Government.

\section{REFERENCES}

[1] C.R. Farrar, K. Worden, An introduction to structural health monitoring, Philosophical Transactions of the Royal Society A: Mathematical, Physical and Engineering Sciences, 365(1851), 303-315, 2007. 
[2] P.C. Chang, A. Flatau, S.C. Liu, Review paper: Health monitoring of civil infrastructure, Structural Health Monitoring, 2(3), 257-267, 2003.

[3] D. Capecchi, F. Vestroni, Monitoring of structural systems by using frequency data, Earthquake Engineering and Structural Dynamics, 28(5), 447-461, 1999.

[4] A. Pau, A. De Sortis, R. Marzellotta, F. Vestroni, Health monitoring of cultural heritage using ambient and forced vibrations, WIT Transaction on the Built Environment, 82, 331$340,2005$.

[5] A. De Sortis, E. Antonacci, F. Vestroni, Dynamic identification of a masonry building using forced vibration tests, Engineering Structures, 27(2), 155-165, 2005.

[6] A. Pau, F. Vestroni, Vibration analysis and dynamic characterization of the Colosseum, Structural Control and Health Monitoring, 15, 1105-1121, 2008.

[7] A. Pau, F. Vestroni, Dynamic characterization of ancient masonry structures, in Advances in Vibration Analysis Research, Intech, Vienna, ISBN: 9789533073910, 2011.

[8] A. Pau, F. Vestroni, Vibration assessment and structural monitoring of the Basilica of Maxentius in Rome, Mechanical Systems and Signal Processing, 41(1-2), 454-466, 2013.

[9] G. Bongiovanni, G. Buffarini, P. Clemente, D. Rinaldis, F. Saitta, M. Nicoletti, A. De Sortis, G. Rossi, Dynamic identification of Palazzo Marchesale in S. Giuliano di Puglia, Proceedings of the $5^{\text {th }}$ International Conference on Structural Engineering, Mechanics and Computation, SEMC, 81-86, 2013.

[10] http://www.metrocspa.it

[11] E. Romani, I. Mammone, S. Moretti, G. Pezzetti, Rome Metro Line Monitoring System: the C Line experience, International Symposium on Field Measurements in Geomechanics, 2018.

[12] UNI 9916:2014 Criteria for the measurement of vibrations and the assessment of their effects on buildings.

[13] V. Gattulli, E. Antonacci, F. Vestroni, Field observations and failure analysis of the Basilica S. Maria di Collemaggio after the 2009 L'Aquila earthquake, Engineering Failure Analysis, 34, 715-734, 2013.

[14] F. Benedettini, A. De Sortis, G. Milana, In field data to correctly characterize the seismic response of buildings and bridges, Bulletin of Earthquake Engineering, 15(2), 643-666, 2017. 